\title{
Patient care activities by community pharmacists in a capitation funding model mental health and addictions program
}

\author{
Andrea L. Murphy ${ }^{1 *}$, David M. Gardner ${ }^{2}$ and Lisa M. Jacobs ${ }^{3}$
}

\begin{abstract}
Background: Community pharmacists are autonomous, regulated health care professionals located in urban and rural communities in Canada. The accessibility, knowledge, and skills of community pharmacists can be leveraged to increase mental illness and addictions care in communities.

Methods: The Bloom Program was designed, developed, and implemented based on the Behaviour Change Wheel and a program of research in community pharmacy mental healthcare capacity building. We evaluated the Bloom Program as a demonstration project using mixed methods. A retrospective chart audit was conducted to examine outcomes and these are reported in this paper.

Results: We collected 201 patient charts from 23 pharmacies in Nova Scotia with 182 patients having at least one or more follow-up visits. Anxiety $(n=126,69 \%)$, depression $(n=112,62 \%)$, and sleep disorders $(n=64,35 \%)$ were the most frequent mental health problems. Comorbid physical health problems were documented in $57 \%(n=104)$. The average number of prescribed medications was 5.5 (range 0 to 24). Sixty seven percent $(n=122)$ were taking multiple psychotropics and $71 \%(n=130)$ reported taking more than one medication for physical health problems. Treatment optimization was the leading reason for enrollment with more than $80 \%$ seeking improvements in symptom management and daily functioning. There were a total of 1233 patient-care meetings documented, of which the duration was recorded in 1098. The median time for enrolling, assessing, and providing follow-up care by pharmacists was 142 min (mean 176, SD 128) per patient. The median follow-up encounter duration was 15 min. A total of 146 patient care encounters were 60 min or longer, representing 13.3\% of all timed encounters.

Conclusions: Pharmacists work with patients with lived experience of mental illness and addictions to improve medication related outcomes including those related to treatment optimization, reducing polytherapy, and facilitating withdrawal from medications. Pharmacists can offer their services frequently and routinely without the need for an appointment while affording patient confidentiality and privacy. Important roles for pharmacists around the deprescribing of various medications (e.g., benzodiazepines) have previously been supported and should be optimized and more broadly implemented. Further research on the best mechanisms to incentivize pharmacists in mental illness and addiction's care should be explored.
\end{abstract}

Keywords: Mental disorders, Community pharmacy services, Pharmacists, Observational study

\footnotetext{
*Correspondence: andrea.murphy@dal.ca

${ }^{1}$ College of Pharmacy and Department of Psychiatry, Dalhousie University,

5968 College St, PO Box 15000, Halifax, NS B3H 4R2, Canada

Full list of author information is available at the end of the article
}

(c) The Author(s). 2018 Open Access This article is distributed under the terms of the Creative Commons Attribution 4.0 International License (http://creativecommons.org/licenses/by/4.0/), which permits unrestricted use, distribution, and reproduction in any medium, provided you give appropriate credit to the original author(s) and the source, provide a link to the Creative Commons license, and indicate if changes were made. The Creative Commons Public Domain Dedication waiver (http://creativecommons.org/publicdomain/zero/1.0/) applies to the data made available in this article, unless otherwise stated. 


\section{Background}

Pharmacists are ideally positioned in community pharmacies to improve patient outcomes in mental illness and addictions care. A recent International Pharmaceutical Federation (FIP) report provided a global overview of how pharmacists contribute to the care and well-being of people living with mental health and addictions problems, including through optimizing treatment outcomes, education, early detection, triage, collaboration, health promotion, policy development, and research [1]. Adherence support has often been identified as a key service pharmacists can offer to people with mental health and addictions problems, however the FIP report illustrates a much broader and more integrated role of the community pharmacist in mental health and addictions [1].

Pharmacists' roles have become increasingly collaborative and clinically-oriented [2] in mental illness and addictions care. Roles have been evolving beyond that of the "drug expert" [3] with a modernized scope [4]. Previous systematic reviews document the improvements in patient satisfaction and outcomes for those with lived experience of illness, such as depression and psychosis, largely due to medication management activities of pharmacists $[5,6]$. The evolution of pharmacists' roles and enhanced clinical service delivery also provides the opportunity to narrow gaps in the mental health system including those related to effectiveness, efficiency, and equality and equity of care $[7,8]$. These roles are possible and supported by a trusting public who frequently access pharmacists' services [9-11]. However, impediments have been described that serve to undermine the potential value of community pharmacists in building on their contributions to mental health and addictions care in their communities [12-19].

In some regions, there is no expectation of complete privacy when visiting a pharmacy and pharmacist workflow demands in some settings can make it difficult to spend sufficient uninterrupted time with a patient $[16,20,21]$. Communication and location of healthcare providers offers an ongoing challenge, one familiar to community pharmacists [22]. Another important barrier, though often overlooked, is that of role expectation. People will have different expectations of their pharmacists, often based on past interactions [23-25]. Role modification can therefore be met with a range of responses [26] taking substantial time and effort to establish comfort and confidence.

Nova Scotia is a province in eastern Canada of approximately 949,500 people [27] served by 303 community pharmacies [28]. Many (urban $=99.2 \%$, rural $=53.3 \%$ ) Nova Scotians live within five kilometres of a community pharmacy [10], making pharmacists accessible healthcare providers, even in rural areas. In 2012, the provincial government released a mental health and addictions strategy
[29]. The strategy included 61 recommendations, of which more than 20 were amenable to pharmacists' involvement and interventions. These included areas such as health promotion and early intervention; knowledge, education, and awareness of the public; collaboration with primary care providers; and access to services [29].

Based on the accessibility of pharmacists with expanding scopes and capabilities [30, 31], a progressive movement supported by government and the public to improve mental illness and addictions services, and an expanding, contextually relevant evidence base in this area [16, 19-21, 32, 33], we designed, developed, and implemented the Bloom Program - the mental health and addictions community pharmacy partnership program of Nova Scotia [34]. The Bloom Program was implemented as a demonstration project with an evaluation to facilitate decision-making around the program's future. In this paper, we describe the program, care activities provided, and outcomes of the Bloom Program demonstration project. Our analyses and inferences are primarily based on our patient chart reviews that served as one component of a broader mixed methods evaluation of the Bloom Program.

\section{Methods \\ Design}

The Bloom Program design was underpinned by a theoretical model of behaviour, the Behaviour Change Wheel $(\mathrm{BCW})$ (Fig. 1) [35, 36], which we used in our previous mental health program development [33]. The BCW was developed from 19 frameworks of behaviour change by Michie and colleagues [36]. At the centre of the BCW, there is a "behaviour system" that includes capability $(\mathrm{C})$, opportunity $(\mathrm{O})$, and motivation $(\mathrm{M})$, which ultimately interact to produce behaviours (B) (COM-B) (Fig. 2). The BCW also includes nine intervention functions and seven policy categories that support intervention design (Fig. 1) [36].

The Theoretical Domains Framework (TDF) domains are mapped to the COM-B component of the BCW [35]. The TDF domains can be used to categorize or explain influences on behaviour and can be linked to the elements of COM-B to determine what intervention functions and/or policy categories may be best suited to the intervention design for changing target behaviours in context. Informed by the BCW, the core components of the Bloom Program, such as conducting community outreach and forming linkages with community mental health and addictions services and supports, and collaborating with other health care providers such as family physicians and psychiatrists, were intended to support pharmacists in their care of patients with lived experience of mental illness and addictions (Table 1).

Additionally, the program was supported by a capitation funding model in which pharmacies received a 


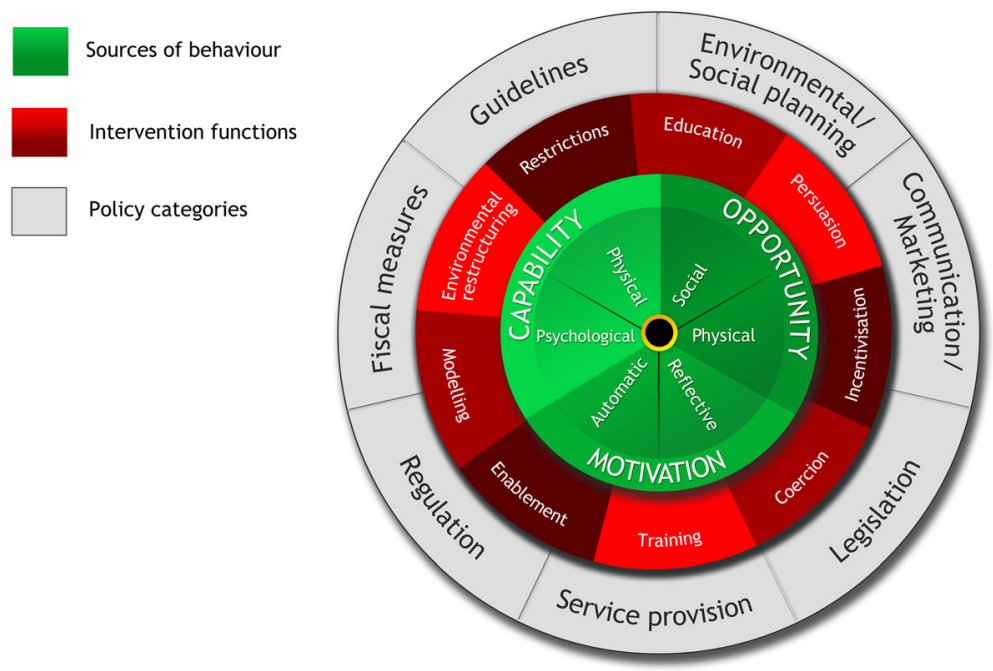

Fig. 1 The Behaviour Change Wheel (BCW) [36]

fixed fee of $\$ 75 /$ month Canadian (CAD) up to six times (\$450/patient CAD) per patient. Fees were paid only during the months when care from pharmacists were received by the patient. If care was interrupted for longer than a month (e.g., due to hospitalization) no fee was paid to the pharmacy. The model of care was longitudinal with regular visits that addressed medications and related health issues (physical, mental, and addictions) that were collaboratively prioritized by the patient, pharmacist, and other members of their circle of care. If continued enrollment was indicated in the pharmacist's judgment, in which new or ongoing medication issues existed, pharmacists could apply to extend a patient's enrollment for another six month fee period at a lower compensation rate of $\$ 30 /$ month CAD. Financial support to implement the Bloom Program and conduct an evaluation was provided by monies allocated through the provincial mental health and addictions strategy fund. The number of participating pharmacies and patients were limited based on the funding available.

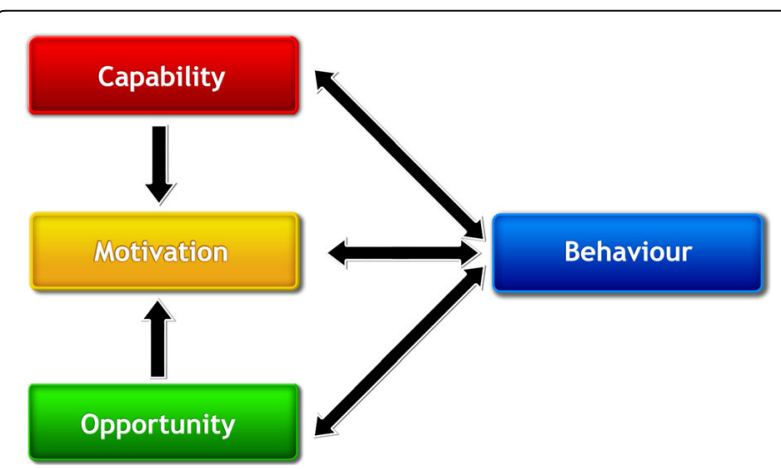

Fig. 2 The Capability Opportunity Motivation - Behaviour (COM-B) model [36]
Governance of the Bloom Program included a multistakeholder steering committee consisting of community members representing people with lived experience of mental illness, pharmacists, physicians, and representatives of the regional health authority, government, and professional advocacy and regulatory organizations of Nova Scotia. A Bloom Program evaluation subcommittee also provided feedback on the evaluation framework, data collection tools, and plans. The Program was implemented as a two-year demonstration project to ensure fitness for purpose.

\section{Bloom program demonstration project timeline}

The demonstration project was completed over 27 months, starting September 2014 and ending for the evaluation of December 2016. The program continued without interruption following the demonstration project's completion.

\section{Pharmacy participants}

A designated lead pharmacist completed a 9-step application process (see Fig. 3) and received approval from the program administrator before the pharmacy was eligible to offer the Bloom Program. An additional criterion was the availability of a fully private consultation room in the pharmacy. To initiate the application process, lead pharmacists either expressed interest online or were informed of the opportunity based on their participation in previous community pharmacy mental illness focused initiatives [33, 37]. Twenty-three pharmacies were recruited to participate over 18 months via three training waves and were informed that a maximum of 20 patients per pharmacy could be enrolled at any one time.

\section{Patient participants}

There were two considerations to determine a patient's eligibility: the presence of one or more 
Table 1 Bloom Program components

\begin{tabular}{|c|c|}
\hline Component & Component description \\
\hline 1. Linkages & Developing and maintaining linkages with community mental health organizations. \\
\hline 2. Outreach & Providing outreach activities by the pharmacy and its pharmacists to support the local mental health community. \\
\hline 3. Collaboration & $\begin{array}{l}\text { Enhancing collaboration and communication with other health providers, especially primary care and mental health } \\
\text { and addictions care services. }\end{array}$ \\
\hline 4. Resources & Developing a local mental health knowledge exchange "resource centre". \\
\hline 5. Training & Providing program-related education and training to all pharmacy team members. \\
\hline $\begin{array}{l}\text { 6. Patient } \\
\text { registration }\end{array}$ & Enrolment of targeted eligible patients by pharmacists with the program. \\
\hline $\begin{array}{l}\text { 7. Enhanced patient } \\
\text { care }\end{array}$ & $\begin{array}{l}\text { Providing enhanced patient support services including: } \\
\text { - Mental health and addictions systems navigation, resources and access support } \\
\text { - Triage of care to appropriate health providers as indicated } \\
\text { - In depth medication therapy management involving enhanced monitoring and overall assessment of addictions and mental } \\
\text { illness as well as physical health disorders and their treatments } \\
\text { - Collaboration with patients, families and other care providers to identify and resolve mental and physical health problems } \\
\text { - Education consultations regarding mental health disorders and their treatment } \\
\text { - Real-time support in person or via telephone during posted pharmacy operations }\end{array}$ \\
\hline 8. Quality assurance & $\begin{array}{l}\text { Pharmacies participating in the program will maintain records demonstrating adherence to the program's critical } \\
\text { components. Participating pharmacies will apply to continue with the program every } 2 \text { years. }\end{array}$ \\
\hline $\begin{array}{l}\text { 9. Program } \\
\text { evaluation }\end{array}$ & A comprehensive evaluation of the Bloom Program. \\
\hline
\end{tabular}

self-identified mental illnesses and the existence of one or more medication-related issues. The list of eligible diagnoses was based on DSM-5 diagnostic categories and was intentionally broad and inclusive (Table 2). Pharmacists were to prioritize enrolling "high priority" patients, which were established based on illness prevalence, frequency of medication-related issues, knowledge of health service needs, and recognition of the important role pharmacists have in the care of people with these diagnoses. The aim was to enroll $70 \%$ or more people with one or more high priority diagnoses. Including the "other diagnoses" group ensured vertical equity of services for more vulnerable groups [38-40] who also have health and medication issues that are within the scope of a pharmacist's practice.

Pharmacists were to indicate which of the five medication-related issues existed at a patient's enrollment (Table 3). Following enrollment, pharmacists and patients met and completed a comprehensive initial assessment and developed a plan to address a prioritized list of health and medication issues. Follow-up care was provided at scheduled meetings and/or convenience meetings (e.g., patient visit or telephone call to the pharmacy) and was determined based on a mutually agreeable schedule of the patient and pharmacist.

\section{Documentation, data collection, and analysis}

The Bloom Program evaluation was conducted using mixed methods with various sources for data collection (e.g., surveys, interviews, enrolment forms, chart abstractions). This paper focuses on quantitative analyses for the retrospective chart review data that was collected. Other results and findings, such as those from qualitative analyses of interviews, will be reported elsewhere.

Participating pharmacies were provided with a complete set of forms to facilitate and document patient care and collaboration activities. Examples of these forms include: enrollment, initial assessment, progress notes, communications with healthcare providers, and discharge. Forms were constructed to support data collection and analyses. For example, check boxes were used to capture enrollment criteria and pharmacists' actions related to follow-up visits. Activity duration was included on all forms to capture pharmacist's time investment. Outcomes of health and medication issues were collected from the discharge form. At discharge, patients were asked to complete a form by documenting the health and medication issues that were identified at the initial assessment and throughout their participation in the Bloom Program. They scored the outcome of each problem as resolved, improved, unchanged, or worse. The pharmacist summarized the actions taken to address each identified problem.

Copies of Bloom Program patient charts maintained at each pharmacy were anonymized by pharmacy staff and securely forwarded to the evaluation team. Data were abstracted and analyzed using descriptive statistics with SPSS and Microsoft Office Excel.

\section{Results}

\section{Patient characteristics}

We collected 201 patient charts from 23 pharmacies in Nova Scotia with 182 patients having at least one or 
Conduct a local environmental scan of mental health \& addictions services, advocacy supports, \& resources. Provide a mental health \& within the pharmacy.

Inform the public that the Bloom Program is offered at this pharmacy. Identified lead pharmacist
participate in live training. within the pharmacy related to the Bloom Program.

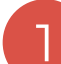

7

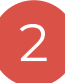

Demonstrate links with local mental health \& addictions services and support groups.

Inform local health providers that the Bloom Program will be offered at the pharmacy.

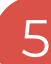

Maintain an in-pharmacy

health professional

library.

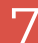

Lead pharmacist to facilitate training of other pharmacy staff.

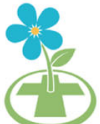

Fig. 3 Nine-step Bloom Program pharmacy application

more follow-up visits after the initial assessment with the pharmacist (Table 4).

\section{Diagnoses}

Among 182 patients with one or more follow-up visits, anxiety $(n=126,69 \%)$, depression $(n=112,62 \%)$, and sleep disorders $(n=64,35 \%)$ were the most frequent patient-identified mental health problems, followed by substance use disorders $(n=29,16 \%)$, post-traumatic stress disorder (PTSD) $(n=27,15 \%)$, and bipolar disorder $(n=20,11 \%)$ (Table 5$)$. Comorbid physical health problems were documented in $57 \%(n=104)$ (Table 5).

\section{Reason for enrollment}

The leading reason patients enrolled in the Bloom Program was for treatment optimization. Over $80 \%$ indicated that they were seeking improvements in symptom management and daily functioning through working more closely with their pharmacist in the program (Table 6). Far fewer patients identified other eligibility criteria for enrolling. Approximately one-quarter identified managing adverse effects and $11 \%$ indicated non-adherence as important issues. Almost 20\% chose the Bloom Program to help simplify their treatment regimen due to concerns of inappropriate medications or to access support in stopping selected medications, usually sedative-hypnotics.

\section{Medication use}

Among program patients who had one or more follow-up visits with the pharmacist, the average number of regularly used prescribed medications was 5.5 (range 0 to 24$)$ (Table 6). Sixty seven percent $(n=122)$ were taking multiple psychotropics and $71 \%(n=130)$ reported taking more than one medication for physical health problems. The most commonly used psychotropic 
Table 2 High priority and other diagnoses for Bloom Program enrollees

\begin{tabular}{l}
\hline High priority diagnoses: \\
Psychosis (e.g., schizophrenia, unspecified psychosis) \\
Bipolar and related disorders (e.g., bipolar disorder types I and II) \\
Depressive disorders (e.g., major depressive disorder) \\
Anxiety disorders (e.g., social anxiety disorder, panic disorder) \\
Obsessive-compulsive and related disorders (e.g., OCD, body \\
dysmorphic disorder) \\
Trauma and stress related disorders (e.g., post-traumatic stress \\
disorder) \\
Other diagnoses: \\
Feeding and eating disorders (e.g., anorexia nervosa, bulimia nervosa) \\
Sleep-wake disorders (e.g., insomnia disorder with episodic, persistent, \\
or recurrent specifier (excluded is acute insomnia), narcolepsy, \\
circadian rhythm sleep-wake disorders) \\
Personality disorder (e.g., borderline personality disorder) \\
Neurodevelopmental disorders (e.g., intellectual disability disorder, \\
Autism, attention-deficit/hyperactivity disorder, tic disorder) \\
Disruptive, impulse-control, and conduct disorders (e.g., oppositional \\
defiant disorder, intermittent explosive disorder, conduct disorder) \\
Substance-related and addictive disorders (e.g., alcohol use disorder; \\
sedative, hypnotic, or anxiolytic use disorder)
\end{tabular}

medications were antidepressants, benzodiazepines and related sedatives, and antipsychotics. Use of nicotine, alcohol, and marijuana were also common (Table 5).

\section{Length, frequency, nature of visits, and disposition}

The pattern of access varied for the 182 patients with one or more follow-up visit. There were a total of 1233 patient-care meetings documented of which the duration was recorded in 1098. Intensity of care was highest early in the program following patient enrollment with more frequent and longer visits that gradually declined as patients progressed through the program (Fig. 4). The median time invested by pharmacists in enrolling, assessing, and providing follow-up care (including direct patient care, communications with other patient care team members, and documentation) was 142 min (mean

Table 3 Medication therapy issue eligibility criteria for Bloom Program patients

Treatment optimization: Following a standard trial of recent mental health/addictions pharmacotherapy, there is non-response or partial response requiring change in pharmacotherapy.

Treatment adverse effect: Experiencing a treatment-limiting adverse effect to current mental health or addictions medication(s) requiring change in pharmacotherapy.

Non-adherence: Medication refusal or non-adherence leading to a current or a near-recent decompensation of mental illness or addiction.

Medication withdrawal: Difficulty tapering and stopping treatment for a mental health or addictions problem in a stable patient.

Inappropriate polytherapy: Taking multiple medications, including psychotropics and non-psychotropics, that is causing functional impairment requiring modifications including medication discontinuation(s) on the basis of safety, redundancy, and absence of indication.
(SD) 176 (128)) per patient. The median follow-up encounter duration was $15 \mathrm{~min}$.

There were a total of 146 patient care encounters of $60 \mathrm{~min}$ or longer, representing $13.3 \%$ of all timed encounters. Two pharmacies were outliers. They accounted for $101(69 \%)$ of all longer patient encounters. In these two pharmacies, appointments of $60 \mathrm{~min}$ or longer accounted for 30 and $44 \%$ of patient encounters, respectively. In the other pharmacies, longer appointments of $60 \mathrm{~min}$ or more accounted for $4.5 \%$ of patient care encounters. Based on the visit pattern of the demonstration project, we estimated a reimbursement rate of $\$ 2.13$ (CAD) per minute of the pharmacist's time.

Patient disposition is shown in Table 7. Completed discharge forms were available for 46 participants. For this group, median duration in the program was six months (183 days, IQR: 155, 247). Thirty percent of patients were lost to follow-up during their participation in the program and $42 \%$ remained in the program. Seventeen requests for enrollment extensions were made by pharmacists with most relating to continued symptoms of mental illness (e.g., depression $(n=8)$, mixed symptoms of illnesses $(n=2)$, anxiety $(\mathrm{n}=2)$, continued substance use (alcohol, tobacco) $(n=2)$, insomnia $(n=1))$, and other reasons such as weight gain $(n=1)$ and discontinuation of medication $(n=1)$.

\section{Pharmacist patient care activities}

The provided progress notes form, which was a semi-structured template for documentation of follow-up encounters, included check box options for pharmacists to indicate the actions taken related to the encounter. These included: medication management, navigation, education, collaboration, triage, and other. These forms were used in 1192 follow-up encounters. Documentation of encounters was evident for 90 other occasions in which the provided Bloom form was not used. A total of 1178 boxes were checked using the provided forms giving an estimate of the distribution of purposes and resulting actions of the follow-up meetings (Fig. 5). The most frequent activity and reason for follow-up meetings with pharmacists related to medication management. This accounted for nearly one half of the actions documented. Collectively, education, navigation, collaboration, triage, and other activities accounted for just over half of pharmacist patient care actions in the Bloom Program. To further elucidate the wider set of actions, we analyzed data from the first follow-up encounter for which 216 actions were recorded, 89 identified as medication management and 127 related to the other activities. There were 78 actions recorded when medication management was not identified as a purpose of the first meeting (navigation: 22, triage: 3, collaboration: 9, education: 21 , and other: 23 ) indicating a high 
Table 4 Demographics of Bloom Program patients

\begin{tabular}{|c|c|c|c|c|}
\hline & All pat & & Patient & 182) \\
\hline & Mean & SD & Mean & SD \\
\hline Age & 48.1 & 15.7 & 47.9 & 16.1 \\
\hline & $\mathrm{n}$ & $\%$ & $n$ & $\%$ \\
\hline Sex & & & & \\
\hline Female & 120 & 59.7 & 114 & 62.6 \\
\hline Male & 81 & 40.3 & 68 & 37.4 \\
\hline Living situation & & & & \\
\hline Family/friends & 131 & 65.2 & 118 & 64.8 \\
\hline Alone & 47 & 23.4 & 44 & 24.2 \\
\hline Group home & 7 & 3.5 & 7 & 3.8 \\
\hline Other & 4 & 2.0 & 4 & 2.2 \\
\hline Unknown & 12 & 6.0 & 9 & 4.9 \\
\hline Marital Status & & & & \\
\hline Married/common law & 83 & 41.3 & 75 & 41.2 \\
\hline Single & 75 & 37.3 & 70 & 38.5 \\
\hline Separated/ divorced & 25 & 12.4 & 22 & 12.1 \\
\hline Unknown & 18 & 9.0 & 15 & 8.2 \\
\hline Occupational status & & & & \\
\hline Employed & 71 & 35.3 & 68 & 37.5 \\
\hline Unemployed & 99 & 49.3 & 87 & 47.8 \\
\hline School & 11 & 5.5 & 10 & 5.5 \\
\hline Unknown & 20 & 10.0 & 17 & 9.3 \\
\hline Education & & & & \\
\hline Less than high school & 27 & 13.4 & 24 & 13.2 \\
\hline High school & 46 & 22.9 & 39 & 21.4 \\
\hline College/university & 65 & 32.3 & 61 & 33.5 \\
\hline Unknown & 63 & 31.3 & 58 & 31.9 \\
\hline Medication coverage & & & & \\
\hline Public insurance & 96 & 47.8 & 87 & 47.8 \\
\hline Private insurance & 78 & 38.8 & 70 & 38.5 \\
\hline Cash & 20 & 10.0 & 18 & 9.9 \\
\hline Unknown & 7 & 3.5 & 7 & 3.8 \\
\hline Physician care & & & & \\
\hline Family physician & 188 & 93.5 & 173 & 95.1 \\
\hline Psychiatrist & 66 & 32.8 & 63 & 34.6 \\
\hline None & 9 & 4.5 & 6 & 3.3 \\
\hline
\end{tabular}

frequency of encounters between pharmacists and patients for purposes other than addressing medication issue. A more detailed analysis of these encounters is ongoing.

\section{Location of patient care activities and interactions}

For patients with one or more follow-up visits, the pharmacist's location was documented in 1039 encounters.
The pharmacist was located at the pharmacy for $95.2 \%$ of the encounters and out of the pharmacy for $4.8 \%$ of encounters. This included encounters at physicians' offices and the patients' home. The telephone was used to facilitate $29.4 \%$ encounters, whereas the majority (70.6\%) were in person. These data indicate that approximately two-thirds of encounters were face-to-face in the pharmacy's private consultation room. 
Table 5 Health status at enrolment into the Bloom Program

\begin{tabular}{|c|c|c|c|c|}
\hline & \multicolumn{2}{|c|}{ All patients $(n=201)$} & \multicolumn{2}{|c|}{ Patients with $\geq 1$ follow-up visit $(n=182)$} \\
\hline & Mean & SD & Mean & SD \\
\hline \multirow[t]{2}{*}{ Number of stated health problems } & 2.7 & 1.4 & 2.7 & 1.4 \\
\hline & $\mathrm{n}$ & $\%$ & $\mathrm{n}$ & $\%$ \\
\hline Participants with mental health and/or addictions problems & 201 & 100 & 182 & 100 \\
\hline Psychotic disorder & 13 & 6.5 & 11 & 6.0 \\
\hline Bipolar disorder & 23 & 11.4 & 20 & 11.0 \\
\hline Depressive disorder & 126 & 62.7 & 112 & 61.5 \\
\hline Anxiety disorder & 139 & 69.2 & 126 & 69.2 \\
\hline Obsessive compulsive disorder & 15 & 7.5 & 15 & 8.2 \\
\hline Post-traumatic stress disorder & 29 & 14.4 & 27 & 14.8 \\
\hline Eating disorder & 8 & 4.0 & 8 & 4.4 \\
\hline Insomnia or other sleep disorder & 72 & 35.8 & 64 & 35.2 \\
\hline Personality disorder & 11 & 5.5 & 11 & 6.0 \\
\hline ADHD & 13 & 6.5 & 13 & 7.1 \\
\hline Disruptive behaviour disorder & 6 & 3.0 & 6 & 3.3 \\
\hline Substance use disorder & 32 & 15.9 & 29 & 15.9 \\
\hline Number of mental health and addictions problems & \multicolumn{2}{|l|}{487} & \multicolumn{2}{|l|}{442} \\
\hline Participants with physical health problems & 113 & 56.2 & 104 & 57.1 \\
\hline Pain and neurological disorders & 77 & 38.3 & 72 & 39.6 \\
\hline Cardiovascular disease & 56 & 27.9 & 53 & 29.1 \\
\hline Gastrointestinal disorders & 29 & 14.4 & 22 & 12.1 \\
\hline Endocrine disorders & 27 & 13.4 & 25 & 13.7 \\
\hline Respiratory disorders & 21 & 10.4 & 18 & 9.9 \\
\hline Other & 47 & 23.4 & 44 & 24.2 \\
\hline Number of physical health problems & 257 & & 234 & \\
\hline \multicolumn{5}{|l|}{ Substance use } \\
\hline Nicotine & 78 & 38.8 & 66 & 36.3 \\
\hline Alcohol & 75 & 37.3 & 68 & 37.4 \\
\hline Marijuana & 36 & 17.9 & 30 & 16.5 \\
\hline Opioids & 23 & 11.4 & 19 & 10.4 \\
\hline
\end{tabular}

\section{Patient outcomes at Bloom Program discharge}

Forty-six patients completed the Bloom Program discharge form with 125 health and medication problems identified and scored. The majority of problems (78\%) were scored as "resolved" or "improved" at discharge from the Bloom Program (Fig. 6). Most patients in this subgroup entered the Bloom Program for treatment optimization $(89 \%, 41 / 46)$.

Two of 125 problems were rated as "worse". A patient with physical disability experienced weight gain in association with an increase in dose of olanzapine while participating in the program, rating the outcome of "weight loss" as worse. Another patient experienced a worsening of depressive symptoms in the first six months of the program and rated this problem as "worse". During her enrollment, her pharmacist recommended starting an antidepressant to her family physician, the prescriber preferred to wait for mental health services involvement. In the interim, the patient experienced a personal crisis that led to a worsening of her mental health condition and a brief hospitalization. She was eventually started on antidepressant treatment with subsequent improvement and stabilization.

The health issues and actions taken to address the health issues as recorded by patients and pharmacists at discharge were varied and included activities other than those specific to medications (Table 8).

\section{Discussion}

Our findings suggest that pharmacists worked closely and frequently with patients in a community pharmacy-based mental illness and addictions program to address mental 
Table 6 Medication issues and medication use at enrollment in the Bloom Program

\begin{tabular}{|c|c|c|c|c|}
\hline & \multicolumn{2}{|c|}{ All patients $(n=201)$} & \multicolumn{2}{|c|}{ Patients with $\geq 1$ follow-up visit $(n=182)$} \\
\hline & $n$ & $\%$ & $\mathrm{n}$ & $\%$ \\
\hline \multicolumn{5}{|l|}{ Medication issues: } \\
\hline Treatment optimization & 162 & 80.6 & 148 & 81.3 \\
\hline Adverse effects & 49 & 24.4 & 44 & 24.2 \\
\hline Non-adherence & 22 & 10.9 & 15 & 8.2 \\
\hline Medication withdrawal & 27 & 13.4 & 23 & 12.6 \\
\hline Inappropriate polytherapy & 12 & 6.0 & 9 & 4.9 \\
\hline \multicolumn{5}{|l|}{ Medications: } \\
\hline Antidepressants & 145 & 72.1 & 130 & 71.4 \\
\hline Benzodiazepines-Z drugs & 107 & 53.2 & 98 & 53.8 \\
\hline Antipsychotics & 58 & 28.9 & 50 & 27.5 \\
\hline Mood stabilizers & 21 & 10.4 & 19 & 10.4 \\
\hline Psychostimulants & 12 & 6.0 & 12 & 6.6 \\
\hline Other Psychotropics & 13 & 6.5 & 12 & 6.6 \\
\hline Opioids & 24 & 11.9 & 23 & 12.6 \\
\hline Opioid replacement therapy & 15 & 7.5 & 14 & 7.7 \\
\hline Multiple psychotropic medications & 136 & 67.7 & 122 & 67 \\
\hline No psychotropic medications & 9 & 4.5 & 7 & 3.8 \\
\hline \multirow[t]{2}{*}{$\geq 1$ physical health medications } & 142 & 70.6 & 130 & 71.4 \\
\hline & Mean & SD & Mean & SD \\
\hline Number of current medications & 5.4 & 4.0 & 5.5 & 4.1 \\
\hline Range of current medications & 0 to 24 & & 0 to 24 & \\
\hline
\end{tabular}

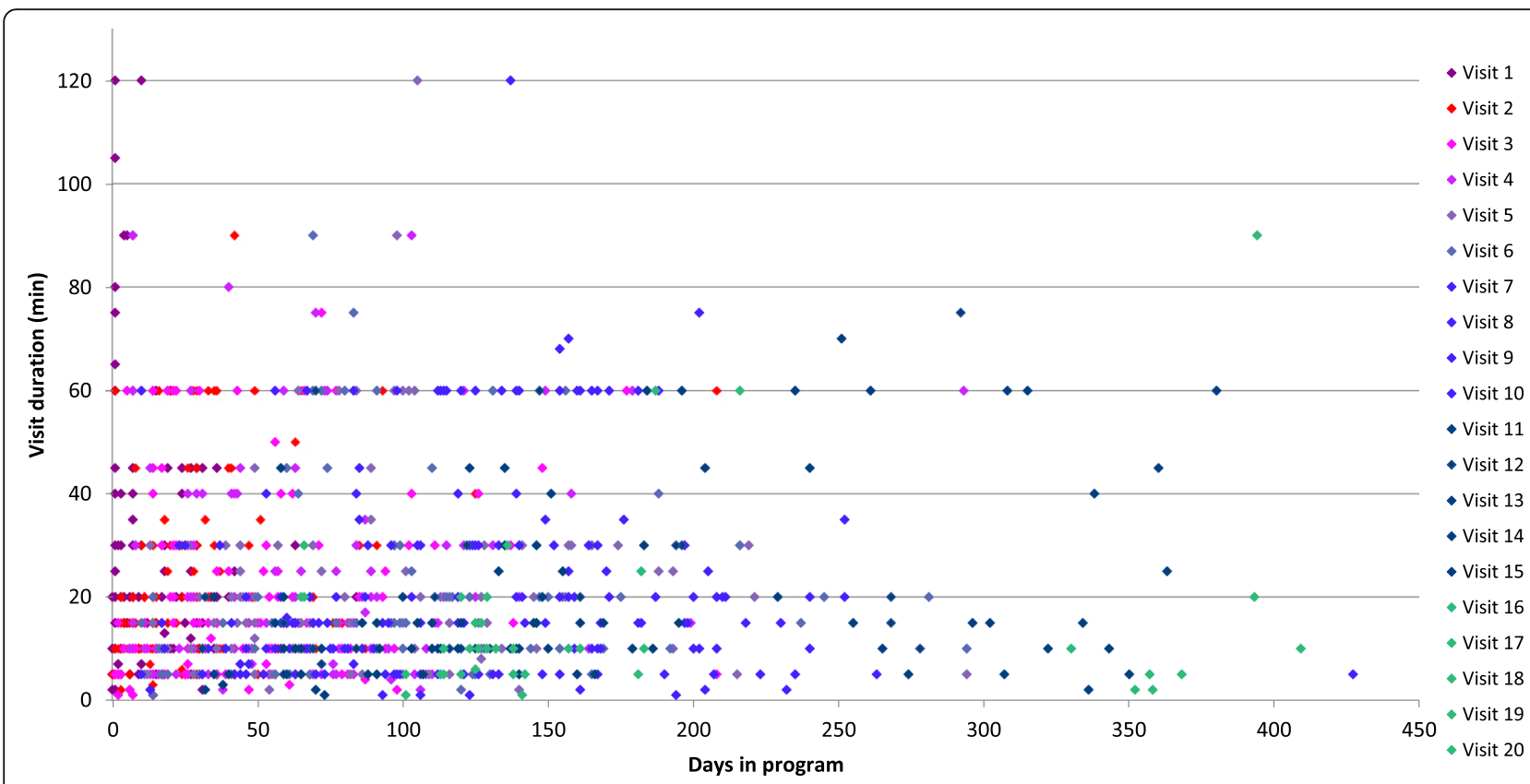

Fig. 4 Density and duration of Bloom Program patient visits 
Table 7 Disposition of Bloom Program patients based on chart review ${ }^{a}$

\begin{tabular}{|c|c|}
\hline Disposition & Number of patients (\%, \\
\hline Still in program & $84(41.8 \%)$ \\
\hline Discharged using discharge form & $46(22.9 \%)$ \\
\hline Assumed discharged (documented discharge plan with > 3 months of inactivity in Bloom Program) & $11(5.5 \%)$ \\
\hline Early loss to follow-up (<3 months in program) & $37(18.4 \%)$ \\
\hline Late loss to follow-up (>3 months in program without documented activity or planned discharge) & $22(11 \%)$ \\
\hline Deceased $^{\mathrm{b}}$ & $1(0.5 \%)$ \\
\hline Total & $201(100 \%)$ \\
\hline
\end{tabular}

${ }^{\mathrm{a}}$ Date of first patient enrolment: 20-Sep-2014. Date of last patient enrolment: 08-Mar-2016. ${ }^{\mathrm{b}}$ One frail elderly participant with multiple health issues died shortly after enrolling in the program

and physical health issues jointly prioritized by patients and pharmacists. Medication optimization actions were at the core of the Bloom Program whereby patients directly engaged pharmacists to support changes in their medication regimen to improve symptomatic and functional outcomes. Pharmacists routinely engaged with patients for purposes that extended beyond medication management, including supporting health system navigation, health and medication education, collaboration with other health providers, and rapid triage of care to other health providers. It may be that some of these other activities did relate to medication management, for example education and collaboration, but pharmacists routinely advocated for and directly pursued their patients' access to other services and supports via their navigational (e.g., referral to community groups and specialty clinics; locating and determining the cost for private psychotherapy) and triage activities. The application process that prioritized building stronger connections with local mental health and addictions services and support organization may have facilitated this. Pharmacists were provided with and oriented to existing and new mental health and addictions resources and directories and were required to identify and make

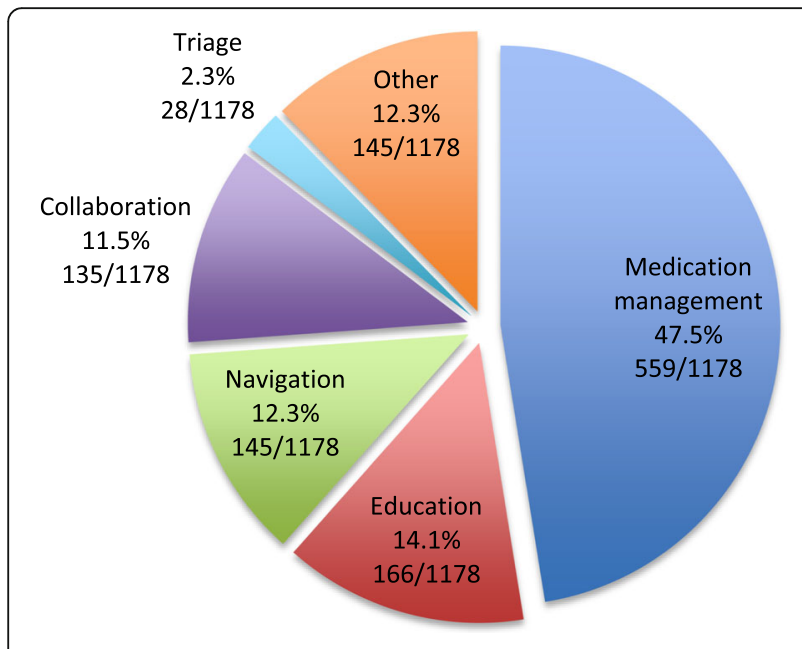

Fig. 5 Purpose of follow-up visits between patients and pharmacists direct connections with local providers and supports related to mental health and addictions. Some of these outreach and navigation roles that fall outside of activities explicitly linked to medication management services are often unrecognized but part of routine practice. More recently, these efforts have been acknowledged and explored through systematic reviews and other methods. Some specific areas of study have included general health coaching, walking groups and exercise programs, smoking cessation, weight management, emergency hormonal contraception, general health promotion or screening (e.g., alcohol problems, cholesterol), services for those who misuse or abuse drugs, and sexual health [3, 41-48]. This analysis of the Bloom Program helps to elucidate and quantify the breadth and extent of pharmacists' activities that go beyond patient-centred medication management.

During the Bloom Program, patients and pharmacists met together privately, frequently, regularly, and for some patients these meetings were long. These frequent and sometimes lengthy visits contrast with usual care in

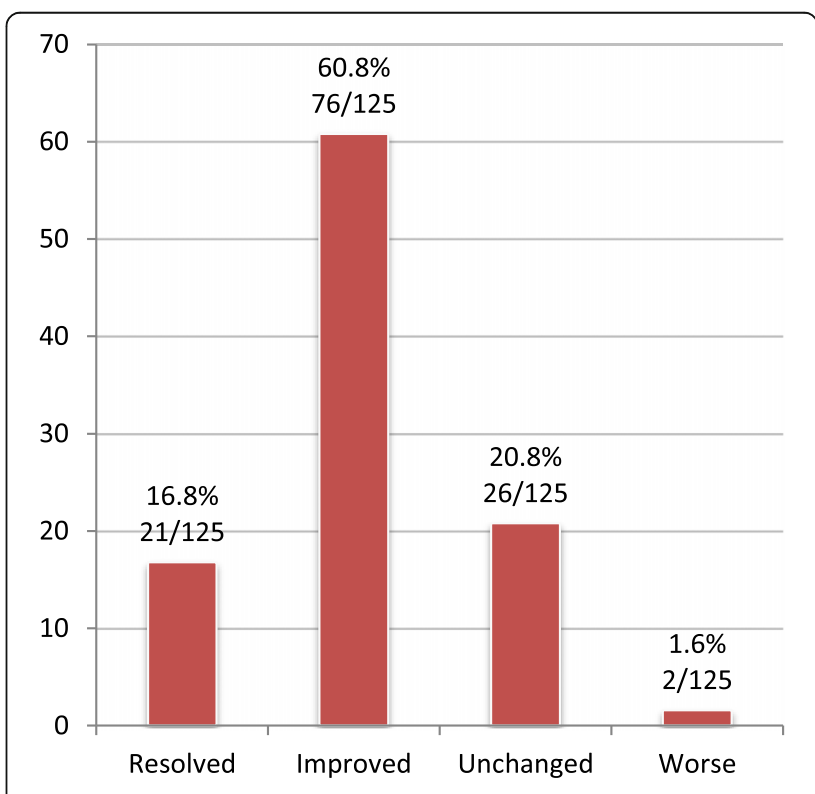

Fig. 6 Patient-reported health problem outcomes at discharge (\%) 
Table 8 Verbatim examples of discharge health and medication issue outcomes ${ }^{a}$

\begin{tabular}{|c|c|c|c|}
\hline & Health issue & Action & Outcome \\
\hline \multirow[t]{15}{*}{$\begin{array}{l}\text { Treatment } \\
\text { optimization }\end{array}$} & Anxiety \& depression & $\begin{array}{l}\text { Has improved through talking as well as having better control over asthma. } \\
\text { Still feels defeated and drained with anxiety more at night. But overall she is } \\
\text { better. }\end{array}$ & Improved \\
\hline & Sleep difficulty & Melatonin and changed Effexor ${ }^{\circledast}$ [venlafaxine] schedule. & Improved \\
\hline & $\begin{array}{l}\text { Insomnia. Average sleep } 3 \mathrm{~h} \text { per night, } \\
\text { multiple medications. }\end{array}$ & Sleep therapy $\left(\mathrm{CBTi}^{\mathrm{b}}\right)$, weaned off hypnotics. & Resolved \\
\hline & Improve depression & Initiation of Cipralex ${ }^{\oplus}[$ scitalopram], monitoring for effectiveness & Improved \\
\hline & $\begin{array}{l}\text { Did not feel comfortable taking } \\
\text { venlafaxine }\end{array}$ & Pharmacist contacted doctor to have patient switched to citalopram. & Resolved \\
\hline & Depressive episodes related to menses & $\begin{array}{l}\text { Increased Paxil }{ }^{\oplus} \text { [paroxetine], augmented with Abilify }{ }^{\oplus} \text { [aripiprazole], } \\
\text { controlled menses via depo [medroxy]progesterone. }\end{array}$ & Improved \\
\hline & Anxiety $+O C D^{c}$ tendencies & $\mathrm{CBT}^{\mathrm{d}}$ option identified and accessed & Improved \\
\hline & Antidepressant ineffective & Sent letter to doctor. He did not act/respond on it. & Unchanged \\
\hline & Pain control & Changed to long-acting Hydromorph Contin ${ }^{\circledast}$ [hydromorphone]. & Improved \\
\hline & Anxiety & Meditation, speaking with pharmacist during Bloom, speaking with doctor. & Improved \\
\hline & Anxiety, anger, paranoia & $\begin{array}{l}\text { No changes in medications. [Patient] feels like this program has helped a } \\
\text { lot. She has decreased anxiety coming into pharmacy, talking to me about } \\
\text { her health/personal and mental health issues and feels comfortable if she } \\
\text { needs help in the future. Still experiencing anger and paranoia - Has talked } \\
\text { to doctor about referral to psychiatrist. }\end{array}$ & Improved \\
\hline & Chronic pain & Acupuncture, tried nortriptyline, massage, chiropractor, yoga & Unchanged \\
\hline & Weight & $\begin{array}{l}\text { Controlled asthma better, therefore allowing her to exercise more and } \\
\text { discontinue prednisone. }\end{array}$ & Improved \\
\hline & PTSD & Sertraline 50 mg started & Unchanged \\
\hline & Seasonal depression & Light therapy suggested to be continued & Improved \\
\hline \multirow[t]{4}{*}{ Adverse effects } & Medication side effects & Met regularly to discuss medication side effects. & Improved \\
\hline & Fatigue/insomnia & $\begin{array}{l}\text { Still unable to work full days. Tamoxifen may be causal but continuing } \times \\
2 \text { years. }\end{array}$ & Unchanged \\
\hline & Sertraline side effect management & Zantac $^{\oplus}$ [ranitidine] 150 mg once daily half hour before sertraline. & Resolved \\
\hline & Decreased sex drive & Switched oral contraceptive. & Resolved \\
\hline \multirow[t]{2}{*}{ Non-adherence } & $\begin{array}{l}\text { Not testing [blood glucose] regularly } \\
\text { because of finances }\end{array}$ & Now on 5 injections per day of insulin - > seeing clinic for supplies & Improved \\
\hline & Not taking meds properly & More organized - and knows what they are for, but now $++^{f}$ financial issues & Unchanged \\
\hline $\begin{array}{l}\text { Medication } \\
\text { withdrawal }\end{array}$ & $\begin{array}{l}\text { Looking for a more natural approach/ } \\
\text { would like to stop all medications. }\end{array}$ & $\begin{array}{l}\text { We discussed current medication but did not think it was a good idea to } \\
\text { stop everything abruptly. }\end{array}$ & Unchanged \\
\hline \multirow[t]{3}{*}{$\begin{array}{l}\text { Inappropriate } \\
\text { polypharmacy }\end{array}$} & $\begin{array}{l}\text { Domperidone }+ \text { Ezetrol }{ }^{\circ} \text { [ezetimibe] not } \\
\text { needed. }\end{array}$ & Contacted doc for discontinuation. [Patient] felt fine without those. & Resolved \\
\hline & Reduction in pill load. & Change in meds. & Improved \\
\hline & Unnecessary OTC ${ }^{g}$ products & Stopped & Resolved \\
\hline \multirow[t]{3}{*}{ Other } & Finances, tax return. & Had an accountant go through papers and get things straightened out. & Resolved \\
\hline & Had not seen doctor for a long time & $\begin{array}{l}\text { Helped encourage visit to doctor's office. Was able to get to doctor and to } \\
\text { get blood work done. }\end{array}$ & Resolved \\
\hline & Overlap in medications from 2 doctors & $\begin{array}{l}\text { Both doctors made aware - > patient now keeping them both informed on } \\
\text { what she's on }\end{array}$ & Improved \\
\hline
\end{tabular}

\footnotetext{
${ }^{a}$ Where medications were written verbatim as brand name or single source products, the generic name has been added in square brackets

${ }^{b}$ CBTi: cognitive behavioural therapy for insomnia

C OCD: obsessive compulsive disorder

${ }^{d}$ CBT: cognitive behavioural therapy

e PTSD: post traumatic stress disorder

f ++: indicates increased or significant

${ }^{9}$ OTC: over the counter
} 
which pharmacists' encounters are usually brief and narrow in focus, for example during antidepressant initiation and prescription refills [13, 14, 49]. Carter et al. [23] showed that engagement with pharmacy services may depend on patient perceptions of how well pharmacists listened to them in previous encounters. Knox et al. [50] also found that patients desire efficient, consistent, and personalized pharmacy services. Patients who enrolled in the Bloom Program could build and strengthen relationships with community pharmacists to work towards common goals. This is supported by the frequency and length of patient encounters triangulated with patient feedback from surveys and interviews regarding the program (data available upon request) in which almost all respondents indicated that the quality of care was very good to excellent and that they would recommend the program to a friend. When satisfied with the quality of pharmacists' care, people willingly build and sustain relationships with pharmacists [51]. The opportunity for private encounters, in person or by telephone, overcomes the privacy issues reported by others as a barrier to patient participation in community pharmacy delivered services [52].

In addition to treatment optimization, nearly one in five Bloom Program patients were seeking the pharmacists' assistance in managing inappropriate polytherapy or medication withdrawal. Two-thirds of the patients were taking multiple psychotropic medications, along with $71 \%$ taking multiple physical health medications. The most commonly used psychotropic medications were antidepressants and sedative-hypnotics, including various benzodiazepines and zopiclone. The latter is particularly relevant given that incident and prevalent use of these medications in Canada continues to rise in adults and seniors and the well-established risks with short- and long-term use [53-55]. The Bloom Program therefore can be used to facilitate deprescribing of benzodiazepines and related medications that often require frequent brief encounters with patients, their pharmacists, and prescribers [56-58]. Pharmacists in the Bloom Program also engaged in resolving physical health and related medication problems for their patients. This is especially important in those with lived experience of mental illness and addictions given the established issues of poor accessibility to care, inequalities in health care service delivery, and relatively poorer physical health outcomes affecting this population [59-68].

Incentivisation was one of the behaviour change intervention functions that was used to support the implementation and sustainability of the Bloom Program as per the Behaviour Change Wheel and Theoretical Domains Framework [35, 36]. Lack of payment for services and problems with payment models have long been cited as barriers to service provision and uptake by pharmacists [69-72]. Data support that incentivized services can help to improve patient outcomes [73], although appropriate payment strategies and mechanisms in pharmacy practice remain largely heterogeneous with the optimal model unknown based on a recent systematic review [74]. Pharmacies were compensated $\$ 450$ for patients who received pharmacist's care over six months, consecutively or with interruptions if there were months in which the patient was unavailable to receive care. The compensation per minute for the pharmacists' time in the Bloom Program, estimated at $\$ 2.13(\mathrm{CDN})$, is in keeping with estimates of compensation for other fee for service clinical activities including medication reviews [75]. This may represent and underestimate as we were not able to estimate pharmacist's time when providing standard care. The use of the capitation funding model in the Bloom Program was intended to support a more holistic and longitudinal approach to patient care in contrast to the typical fee-for-service structure in pharmacy practice. However, the capitation funding model requires further research given the age of some of the existing research in this area [76-79] and its co-existence with other payment models currently used in pharmacy practice. The extent to which the payment model influenced pharmacists in their recruitment and care of patients to the program is not known but should be explored given that other research of physicians using capitation and fee for service payment demonstrates selection of patients may occur based on their risk and complexity [80].

\section{Limitations}

The Bloom Program was not designed as a controlled trial and therefore the results should be interpreted accordingly.

\section{Conclusions}

Pharmacist work with patients with lived experience mental illness and addictions to improve medication related outcomes including those related to treatment optimization, reducing polytherapy, and facilitating withdrawal from medications. Pharmacists can offer their services frequently and routinely without the need for an appointment while affording patient confidentiality and privacy. Given the substantial use of psychotropic medications including polypharmacy, efforts should be made to leverage the strengths and skills of professionals such as pharmacists in efforts to facilitate medication management. Important roles for pharmacists around the deprescribing of inappropriate medications (e.g., benzodiazepines) have previously been supported and should be optimized and more broadly implemented. Further research on the best mechanisms to incentivize pharmacists in mental illness and addiction's care should be explored. 


\section{Acknowledgements}

Thank you to Vanessa Sherwood and Jennifer Dixon for their work on the Bloom Program administration and initial program evaluation framework, respectively. Thank you to the Bloom Program Steering Committee members and the Evaluation Subgroup Committee for their guidance and feedback throughout the Program. Thank you to all the pharmacists and pharmacy team members in Nova Scotia who served their communities as Bloom Program pharmacies.

\section{Funding}

Funding for the Bloom Program was received through the Mental Health and Addictions Strategy of Nova Scotia through the Department of Health and Wellness of Nova Scotia. The funding agency was not involved in the design, interpretation, or writing of the manuscript.

\section{Availability of data and materials}

The dataset is not publicly available due to the potential for breaches of privacy and confidentiality.

\section{Authors' contributions}

ALM and DMG conceived the idea for the Bloom Program. ALM, DMG, LMJ, conducted the data collection, analysis and interpretation of findings. ALM drafted the initial manuscript. ALM, DMG, LMJ participated in examining the interpretation, critical reviewing, providing feedback, and approving the final version of the manuscript.

\section{Authors' information}

ALM and DMG are academic faculty at Dalhousie University, Halifax, Nova Scotia, Canada. LMJ is an independent program evaluator in Halifax, NS. Our research program is focused on designing, developing, and implementing interventions for community pharmacists caring for people with lived experience of mental illness and addictions in primary health care.

\section{Ethics approval and consent to participate}

Dalhousie University Research Ethics Board reviewed the demonstration project proposal and ethics submission and determined that it constituted program evaluation. A formal ethics review was therefore not provided. A privacy impact assessment was completed and approved by the government of Nova Scotia in accordance with provincial privacy legislation.

\section{Competing interests}

The authors declare that they have no competing interests.

\section{Publisher's Note}

Springer Nature remains neutral with regard to jurisdictional claims in published maps and institutional affiliations.

\section{Author details}

${ }^{1}$ College of Pharmacy and Department of Psychiatry, Dalhousie University, 5968 College St, PO Box 15000, Halifax, NS B3H 4R2, Canada. ${ }^{2}$ Department of Psychiatry and College of Pharmacy, Dalhousie University, QEII HSC, AJLB 7517, 5909 Veterans' Memorial Lane, Halifax, NS B3H 2E2, Canada. ${ }^{3}$ Independent Evaluator, Contact Consulting, Halifax, NS, Canada.

Received: 7 September 2017 Accepted: 14 May 2018

Published online: 14 June 2018

\section{References}

1. International Pharmaceutical Federation (FIP). Focus on mental health: the contribution of the pharmacist. 2015. http://www.fip.org/files/Focus_on_ mental_health_-final.pdf. Accessed 11 July 2016.

2. Rubio-Valera $\mathrm{M}$, Chen TF, O'Reilly CL. New roles for pharmacists in community mental health care: a narrative review. Int J Environ Res Public Health. 2014;11:10967-90.

3. Eades CE, Ferguson JS, O'Carroll RE. Public health in community pharmacy: a systematic review of pharmacist and consumer views. BMC Public Health. 2011;11:582

4. Laurant M, Harmsen M, Wollersheim H, Grol R, Faber M, Sibbald B. The impact of nonphysician clinicians: do they improve the quality and costeffectiveness of health care services? Med Care Res Rev. 2009;66:365-89S.
5. Finley PR, Crismon ML, Rush AJ. Evaluating the impact of pharmacists in mental health: a systematic review. Pharmacotherapy. 2003;23:1634-44.

6. Bell S, McLachlan AJ, Aslani P, Whitehead P, Chen TF. Community pharmacy services to optimise the use of medications for mental illness: a systematic review. Aust New Zealand Health Policy. 2005;2:29.

7. Anonymous. Changing Directions, Changing Lives: the Mental Health Strategy for Canada. Calgary: Mental Health Commission of Canada; 2012.

8. Kirby MJL, Keon WJ. The Standing Senate Committee on Social Affairs, Science and Technology. Out of the shadows at last: highlights and recommendations. Ottawa: Senate of Canada; 2006.

9. Wazaify M, Shields E, Hughes CM, McElnay JC. Societal perspectives on overthe-counter (OTC) medicines. Fam Pract. 2005;22:170-6.

10. Law MR, Heard D, Fisher J, Douillard J, Muzika G, Sketris IS. The geographic accessibility of pharmacies in Nova Scotia. Can Pharm J (Ott). 2013;146:39-46.

11. Lynas K. Professionals you can trust: pharmacists top the list again in Ipsos Reid survey. Can Pharm J (Ott). 2012;145:55.

12. Scheerder G, De Coster I, Van Audenhove C. Pharmacists' role in depression care: a survey of attitudes, current practices, and barriers. Psychiatr Serv. 2008:59:1155-60.

13. Black E, Murphy AL, Gardner DM. Community pharmacist services for people with mental illnesses: preferences, satisfaction, and stigma. Psychiatr Serv. 2009;60:1123-7.

14. Gardner DM, Murphy AL, Woodman AK, Connelly S. Community pharmacy services for antidepressant users. Int J Pharm Pract. 2001;9:217-24.

15. Renberg T, Wichman Tornqvist K, Kalvemark Sporrong S, Kettis Lindblad A, Tully MP. Pharmacy users' expectations of pharmacy encounters: a Q-methodological study. Health Expect. 2011;14:361-73.

16. Murphy AL, Szumilas M, Rowe D, Landry K, Martin-Misener RM, Kutcher S, Gardner DM. Pharmacy students' experience in community pharmacy mental health services provision. Can Pharm J. 2014;147:55-65.

17. Crump K, Boo G, Liew FS, Olivier T, So C, Sung JY, Wong CH, Shaw J, Wheeler A. New Zealand community pharmacists' views of their roles in meeting medicine-related needs for people with mental illness. Res Social Adm Pharm. 2011;7:122-33.

18. Mey A, Fowler JL, Knox K, Shum DH, Fejzic J, Hattingh L, McConnell D, Wheeler A. Review of community pharmacy staff educational needs for supporting mental health consumers and carers. Community Ment Health J. 2014;50:59-67.

19. Gardner DM. Competent psychopharmacology. Can J Psychiatr. 2014;59:406-11.

20. Murphy AL, Martin-Misener R, Kutcher SP, O'Reilly C, Chen TF, Gardner DM. From personal crisis care to convenience shopping: an interpretive description of the experiences of people with mental illness in community pharmacies. BMC Health Serv Res. 2016;16:569.

21. Murphy AL, Phelan H, Haslam S, Martin-Misener R, Martin-Misener R, Kutcher S, Gardner DM. Community pharmacists' experiences in mental illness and addictions care: a qualitative study. Subst Abuse Treat Prev Policy. 2016;11:6.

22. Freeman C, Cottrell WN, Kyle G, Williams I, Nissen L. Integrating a pharmacist into the general practice environment: opinions of pharmacist's, general practitioner's, health care consumer's, and practice manager's. BMC Health Serv Res. 2012;12:229.

23. Carter SR, Moles R, White L, Chen TF. The impact of patients' perceptions of the listening skills of the pharmacist on their willingness to re-use home medicines reviews: a structural equation model. Res Social Adm Pharm. 2015;11:163-75.

24. Guirguis $L M$, Chewning BA. Role theory: literature review and implications for patient-pharmacist interactions. Res Social Adm Pharm. 2005;1:483-507.

25. Bishop AC, Boyle TA, Morrison B, Barker JR, Zwicker B, Mahaffey T, Murphy A. Public perceptions of pharmacist expanded scope of practice services in Nova Scotia. Can Pharm J (Ott). 2015;148:274-83.

26. Schindel TJ, Yuksel N, Breault R, Daniels J, Varnhagen S, Hughes CA. Perceptions of pharmacists' roles in the era of expanding scopes of practice. Res Social Adm Pharm. 2017;13:148-61.

27. Estimates of population, by age group and sex for July 1, Canada, provinces and territories. http://www5.statcan.gc.ca/cansim/a26?lang=eng\&retrLang= eng\&id $=0510001 \& \&$ pattern $=\&$ stBy Val $=1 \& p 1=1 \& p 2=37 \&$ tabMode $=$ dataTable\&csid=. Accessed 10 Dec 2016.

28. National Statistics: Provincial/Territorial Statistics - Pharmacies. http:// napra.ca/national-statistics.

29. Mental Health Commission of Canada. Changing directions, changing lives: the mental health strategy for Canada. Calgary: Mental Health Commission of Canada; 2012. 
30. Tannenbaum C, Tsuyuki RT. The expanding scope of pharmacists' practice: implications for physicians. CMAJ. 2013;185:1228-32.

31. Morrison J. Expanded pharmacy practice: where are we, and where do we need to go? Can Pharm J (Ott). 2013;146:365-7.

32. Murphy AL, Martin-Misener R, Kutcher SP, Gardner DM. Pharmacists' performance in a telephone-based simulated patient study after a mental health capacity-building program. Int J Clin Pharm. 2015;37:1009-13.

33. Murphy AL, Gardner DM, Kutcher SP, Martin-Misener R. A theory-informed approach to mental health care capacity building for pharmacists. Int J Ment Health Syst. 2014;8:46.

34. The Bloom Program http://bloomprogram.ca/. Accessed 07 May 2018.

35. Cane J, O'Connor D, Michie S. Validation of the theoretical domains framework for use in behaviour change and implementation research. Implement Sci. 2012;7:37.

36. Michie S, van Stralen MM, West R. The behaviour change wheel: a new method for characterising and designing behaviour change interventions. Implement Sci. 2011;6:42.

37. More Than Meds. www.morethanmeds.com. Accessed 07 May 2018.

38. Mangalore R, Knapp M. Equity in mental health. Epidemiol Psichiatr Soc. 2006;15:260-6.

39. Saxena S, Thornicroft $G$, Knapp M, Whiteford H. Resources for mental health: scarcity, inequity, and inefficiency. Lancet. 2007:370:878-89.

40. Aday LA, Begley CE, Lairson DR, Slater CH, Richard AJ, Montoya IDA. Framework for assessing the effectiveness, efficiency, and equity of behavioral healthcare. Am J Manag Care. 1999;5 Spec No:SP25-44.

41. Fanous A, Kier K, Rush MJ, Terrell S. Impact of a 12-week, pharmacistdirected walking program in an established employee preventive care clinic. Am J Health Syst Pharm. 2014;71:1219-25.

42. Brown TJ, Todd A, O'Malley C, Moore HJ, Husband AK, Bambra C, Kasim A, Sniehotta FF, Steed L, Smith S, Nield L, Summerbell CD. Community pharmacy-delivered interventions for public health priorities: a systematic review of interventions for alcohol reduction, smoking cessation and weight management, including meta-analysis for smoking cessation. BMJ Open. 2016;6:e009828.

43. Lonie JM, Austin Z, Nguyen R, Gill I, Tsingos-Lucas C. Pharmacist-based health coaching: a new model of pharmacist-patient care. Res Social Adm Pharm. 2017;13:644-52.

44. Brown S, Henderson E, Sullivan C. The feasibility and acceptability of the provision of alcohol screening and brief advice in pharmacies for women accessing emergency contraception: an evaluation study. BMC Public Health. 2014;14:1139.

45. Lenz TL, Stading JA. Lifestyle modification counseling of patients with dyslipidemias by pharmacists and other health professionals. J Am Pharm Assoc (2003). 2005;45:709-13.

46. Couchenour RL, Carson DS, Segal AR. Patients' views of pharmacists as providers of smoking cessation services. J Am Pharm Assoc (Wash). 2002:42:510-2.

47. Dhital R, Whittlesea CM, Norman IJ, Milligan P. Community pharmacy service users' views and perceptions of alcohol screening and brief intervention. Drug Alcohol Rev. 2010;29:596-602.

48. Krska J, Mackridge AJ. Involving the public and other stakeholders in development and evaluation of a community pharmacy alcohol screening and brief advice service. Public Health. 2014;128:309-16.

49. Chong WW, Aslani P, Chen TF. Adherence to antidepressant medications: an evaluation of community pharmacists' counseling practices. Patient Prefer Adherence. 2013;7:813-25.

50. Knox K, Fejzic J, Mey A, Fowler JL, Kelly F, McConnell D, Hattingh L, Wheeler AJ. Mental health consumer and caregiver perceptions of stigma in Australian community pharmacies. Int I Soc Psychiatry. 2014;60:533-43.

51. Sakharkar P, Bounthavong M, Hirsch JD, Morello CM, Chen TC, Law AV Development and validation of PSPSQ 2.0 measuring patient satisfaction with pharmacist services. Res Social Adm Pharm. 2015;11:487-98.

52. Fleming ML, Ferries EA, Hatfield MD, Atreja N, Yucel A, Rane PP, Sharma M, Wang $X$. Patients' beliefs regarding counseling provided by community pharmacists: an application of the theory of planned behaviour. JPHSR. 2015;6:77-9.

53. Alessi-Severini S, Bolton JM, Enns MW, Dahl M, Collins DM, Chateau D, Sareen J. Use of benzodiazepines and related drugs in Manitoba: a population-based study. CMAJ Open. 2014;2:E208-16.

54. Alessi-Severini S, Bolton JM, Enns MW, Dahl ME, Chateau D, Collins DM, Sareen J. Sustained use of benzodiazepines and escalation to high doses in a Canadian population. Psychiatr Serv. 2016;67:1012-8.
55. Tannenbaum C, Farrell B, Shaw J, Morgan S, Trimble J, Currie J, Turner J, Rochon P, Silvius J. An ecological approach to reducing potentially inappropriate medication use: Canadian Deprescribing network. Can J Aging. 2017:36:97-107.

56. Martin P, Tannenbaum C. Use of the EMPOWER brochure to deprescribe sedative-hypnotic drugs in older adults with mild cognitive impairment. BMC Geriatr. 2017;17:37.

57. Tannenbaum C, Martin P, Tamblyn R, Benedetti A, Ahmed S. Reduction of inappropriate benzodiazepine prescriptions among older adults through direct patient education: the EMPOWER cluster randomized trial. JAMA Intern Med. 2014;174:890-8.

58. Pardo D, Miller L, Chiulli D. Implementation of a pharmacy consult to reduce co-prescribing of opioids and benzodiazepines in a veteran population. Subst Abus. 2017;38:157-60.

59. Saari KM, Lindeman $S M$, Viilo KM, Isohanni $M K$, Jarvelin $M R$, Lauren $L H$, Savolainen MJ, Koponen HJ. A 4-fold risk of metabolic syndrome in patients with schizophrenia: the northern Finland 1966 birth cohort study. J Clin Psychiatry. 2005;66:559-63.

60. Starkes JM, Poulin CC, Kisely SR. Unmet need for the treatment of depression in Atlantic Canada. Can J Psychiatr. 2005;50:580-90.

61. Vasiliadis HM, Lesage A, Adair C, Boyer R. Service use for mental health reasons: cross-provincial differences in rates, determinants, and equity of access. Can J Psychiatr. 2005;50:614-9.

62. De Hert M, Peuskens J, van Winkel R. Mortality in patients with schizophrenia. Lancet. 2009:374:1591.

63. Kisely S, Quek LH, Pais J, Lalloo R, Johnson NW, Lawrence D. Advanced dental disease in people with severe mental illness: systematic review and meta-analysis. Br J Psychiatry. 2011;199:187-93.

64. Lawrence D, Kisely S, Pais J. The epidemiology of excess mortality in people with mental illness. Can J Psychiatr. 2010;55:752-60.

65. Kisely S, Campbell LA, Wang Y. Treatment of ischaemic heart disease and stroke in individuals with psychosis under universal healthcare. Br J Psychiatry. 2009:195:545-50.

66. Kisely S, Sadek J, MacKenzie A, Lawrence D, Campbell LA. Excess cancer mortality in psychiatric patients. Can J Psychiatr. 2008;53:753-61.

67. Kisely S, Smith M, Lawrence D, Cox M, Campbell LA, Maaten S. Inequitable access for mentally ill patients to some medically necessary procedures. CMAJ. 2007:176:779-84.

68. Kisely S, Simon G. An international study of the effect of physical ill health on psychiatric recovery in primary care. Psychosom Med. 2005: 67:116-22.

69. Roberts AS, Benrimoj SI, Chen TF, Williams KA, Aslani P. Practice change in community pharmacy: quantification of facilitators. Ann Pharmacother. 2008:42:861-8.

70. Smith MA, Spiggle S, McConnell B. Strategies for community-based medication management services in value-based health plans. Res Social Adm Pharm. 2017;13:48-62.

71. Wells KM, Thornley T, Boyd MJ, Boardman HF. Views and Experiences of community pharmacists and superintendent pharmacists regarding the new medicine Service in England prior to implementation. Res Social Adm Pharm. 2014;10:58-71

72. Jones EJ, Mackinnon NJ, Tsuyuki RT. Pharmaceutical care in community pharmacies: practice and research in Canada. Ann Pharmacother. 2005;39. 1527-33.

73. Hatah E, Braund R, Tordoff J, Duffull SB. A systematic review and metaanalysis of pharmacist-led fee-for-services medication review. Br J Clin Pharmacol. 2014;77:102-15.

74. Chan P, Grindrod KA, Bougher D, Pasutto FM, Wilgosh C, Eberhart G, Tsuyuki RA. Systematic review of remuneration Systems for Clinical Pharmacy Care Services. Can Pharm J. 2017:141:102-12.

75. Houle SK, Grindrod KA, Chatterley T, Tsuyuki RT. Paying pharmacists for patient care: a systematic review of remunerated pharmacy clinical care services. Can Pharm J (Ott). 2014;147:209-32.

76. Lipson DP, Yesalis CE 3rd, Kohout FJ, Norwood GJ. Capitation payment for medicaid pharmacy services: impact on non-medicaid prescriptions. Med Care. 1981;19:342-53.

77. Norwood GJ, Helling DK, Burmeister LF, Jones ME, Yesalis CE 3rd, Fisher WP, Lipson DP. Effects of capitation payment for pharmacy services on pharmacist-dispensing and physician-prescribing behavior: II. Therapeutic category analysis, over-the-counter drug usage, and drug interactions. Drug Intell Clin Pharm. 1981;15:656-64. 
78. Yesalis CE 3rd, Lipson DP, Norwood GJ, Helling DK, Burmeister LF, Jones ME, Fisher WP. Capitation payment for pharmacy services. I Impact on drug use and pharmacist dispensing behavior. Med Care. 1984;22:737-45.

79. Yesalis CE 3rd, Norwood GJ, Helling DK, Lipson DP, Mahrenholz RJ, Burmeister LF, Jones ME, Fisher WP. Capitation payment for pharmacy services. II Impact on costs. Med Care. 1984;22:746-54.

80. Rudoler D, Laporte A, Barnsley J, Glazier RH, Deber RB. Paying for primary care: a cross-sectional analysis of cost and morbidity distributions across primary care payment models in Ontario Canada. Soc Sci Med. 2015;124:18-28.

Ready to submit your research? Choose BMC and benefit from:

- fast, convenient online submission

- thorough peer review by experienced researchers in your field

- rapid publication on acceptance

- support for research data, including large and complex data types

- gold Open Access which fosters wider collaboration and increased citations

- maximum visibility for your research: over $100 \mathrm{M}$ website views per year 